\title{
REVOLUCIÓN DE 1868 , GOBIERNO POR DECRETO Y ORÍGENES \\ DE LA CONVALIDACIÓN PARLAMENTARIA DE LOS DECRETOS-LEYES
}

\author{
ASUNCIÓN DE LA IGLESIA CHAMARRO \\ Profesora de Derecho Constitucional \\ Universidad de Navarra
}




\section{SUMARIO}

I. Sistema de fuentes y sistema politico. II. La ReVolución de 1868 Y el GOBIERNO POR DECRETO. III. EL PROYECTO DE LEY DE CONVERSIÓN DE LOS DECRETOS DEL GoBIERNO PROVISIONAL. 


\section{REVOLUCIÓN DE 1868, GOBIERNO POR DECRETO Y ORÍGENES \\ DE LA CONVALIDACIÓN PARLAMENTARIA DE LOS DECRETOS-LEYES}

POR

ASUNCIÓN DE LA IGLESIA CHAMARRO

Profesora de Derecho Constitucional

Universidad de Navarra

\section{SISTEMA DE FUENTES Y SISTEMA POLÍTICO}

Estudiar el sistema real de producción dispositiva es otra forma de acercarse al régimen político de un país en un momento histórico concreto. $Y$ es que el ejercicio del poder en el seno del Estado se expresa también en la facultad de disponer jurídicamente por los órganos constitucionales principales a través de los instrumentos dispositivos que les son propios. Por eso, el modelo de producción dispositiva es proyección del sistema político vigente y-como dice bien Pérez Royo- refleja el equilibrio entre los distintos órganos dotados de capacidad normativa constitucionalmente reconocidos ${ }^{1}$. De esta manera, el manejo de los instrumentos dispositivos propios de Parlamento y Gobierno muestra algo más que una manifestación de preferencias a

1 Pérez Rovo, J., Las fuentes del Derecho, Tecnos, Madrid, 1984, pág. 14. 
la hora de elegir entre ley formal y decreto como principales cauces de emisión de disposiciones, y deja al descubierto la dinámica real del sistema político al conocer los pesos específicos de los «poderes del Estadon.

Si los llamados poderes del Estado contemplados desde la autoría real de las disposiciones se difuminan con frecuencia en el actual Estado de partidos, en el siglo XIX, y en el Sexenio Revolucionario de manera más intensa, estos poderes y el haz funcional que les es propio están en período de afirmación y consolidación. De una parte, la parlamentarización de la monarquía con la emergencia del Gobierno como órgano político diferenciado, y de otra, la lucha por la vigencia real del principio constitucional de división de poderes, otorgan un valor extraordinario al deslinde del "dominio de la ley" y del decreto como proyección en el sistema de fuentes del reparto de funciones característico del modelo constitucional cuyo establecimiento se pretende.

Durante el periodo de la Historia de España que comienza con la Revolución de septiembre de 1868 y termina con el golpe de Estado de diciembre de 1874 que abre la puerta a la Restauración de la Monarquía en la dinastía de Borbón, la publicación oficial, a la sazón la Gaceta de Madrid, permite seguir en las disposiciones jurídicas concretas esos seis años complejos, ricos y convulsos donde Monarquía, República, Dictadura, guerras y Gobiernos Provisionales se suceden y convergen. Precisamente por la inestabilidad del sistema, en la que transcurren largos períodos con unas Cortes disueltas, $o$ en las que las guerras carlista y cubana conducen al estado de excepción, no sería correcto hablar de sistema de fuentes del Sexenio revolucionario, si por sistema se entiende el conjunto de elementos ordenados y racionalmente relacionados entre sí. El estudio de la producción dispositiva en el Sexenio muestra que nos encontramos ante uno de estos períodos de cambio y crisis continuos donde las brevísimas etapas de reparto más o menos respetado de la capacidad normativa entre Gobierno y Parlamento dan paso a períodos críticos donde el decreto se convierte en instrumento dispositivo hegemónico, en una manifestación - siguiendo a Santi Romano- de la necesidad como fuente del Derecho. De esta manera, como veremos, en estos años el decreto emerge en la que es su configuración histórica y etimológica por antonomasia: el decreto como instrumento de crisis ${ }^{2}$.

2 De la Iglesia Chamarro, M. A., El gobierno por decreto, Pamplona, 1997, págs. 24 y ss. 
En efecto, tanto tras los meses que siguen a la Revolución de septiembre de 1868, como tras la proclamación de la I República, los Gobiernos provisionales que responderán al modelo típico de concentración ejercerán el poder supremo por decreto.

Sin embargo, en otros períodos - escasos- de cierta estabilidad, con las Cortes reunidas y desempeñando la función legislativa, $y$ a veces también constituyente, el principio de división de poderes se afirma con absoluta convicción como pilar del sistema constitucional $y$, en consecuencia, los campos propios de la ley y el decreto estarán delimitados, al menos desde una perspectiva teórica. Así, tanto la Constitución de 1869 como el Proyecto de Constitución republicana y federal de 1873 atribuyen en exclusiva a las Cortes el Poder Legislativo como expresión de la soberanía Nacional de que son depositarias (arts. 32 y 34 CE 1868 y art. 46 del Proyecto de CE 1873).

Esos dos factores -el gobierno por decreto en los períodos de inestabilidad y la afirmación del principio de división de poderes- propiciarán que sea precisamente en el contexto de la Revolución liberal de 1868 donde tenga lugar el que muy probablemente sea el primer precedente en España de lo que hoy, siguiendo la letra del artículo 86.2 $\mathrm{CE}$, llamamos "convalidación de los decretos leyes". La propia comisión parlamentaria que elaboró el Dictamen sobre el proyecto de ley remitido por el Gobierno, para «que fueran tenidos y obedecidos como leyes los decretos expedidos por el Gobierno provisional", se refiere en su Dictamen a lo novedoso del procedimiento que se sustancia ante las Cortes Constituyentes:

"La Comisión encargada de examinar el proyecto de ley presentado por el Poder ejecutivo para la probación de los decretos publicados por el Gobierno provisional desde su instalación hasta las Cortes Constituyentes, le ha estudiado detenidamente, comenzando por definir el interés y el objeto á que este proyecto responde, y el carácter y la extensión de la obra que las Cortes le han encomendado.

Este proyecto de ley no tiene precedentes en los fastos parlamentarios de nuestro país. Ni el Gobierno Provisional, nacido de la revolución de 1836, ni el de 1854, producto también de un movimiento popular muy semejante, llevaron á las Cortes Constituyentes de estas dos épocas ningún proyecto de ley en demanda de su aprobación á las medidas que habían dictado mientras rigieron los destinos del país y hasta que las Cortes se constituyeron y resignaron en ellas sus poderes ${ }^{3}$.

3 Diario de Sesiones de las Cortes Constituyentes, Apéndice $4 .^{\circ}, \mathrm{n} .^{\circ} 41,3$ IV-1869. 
(Dictamen de la Comisión sobre el proyecto de ley para que se tengan y obedezcan como leyes todos los decretos expedidos por el Gobierno provisional, Diario de Sesiones de las Cortes Constituyentes, n. $^{\circ} 41$, apéndice 4, 3-abril-1869).

Si esto es novedad en España, no lo es en otros lugares. En la Europa continental circulaba ya tanto la figura del decreto-ley como la necesidad de sanación de los mismos. La Corte de Casación francesa habría acuñado en 1835 la expresión "décrets-lois» para aquellos decretos dictados.por Napoleón I durante el Imperio y que afectaban a ámbitos constitucionalmente reservados al Poder Legislativo. En aquella ocasión, para la sanación de los decretos se entendió de aplicación la técnica del silencio positivo o la convalidación presunta de los decretos ante la ausencia de una oposición expresa del Senado, responsable de la constitucionalidad de los actos del Gobierno ${ }^{4}$. Sin embargo, como veremos, el Gobierno provisional de Serrano instalado en 1869, prefirió seguir un modelo de pronunciamiento expreso de las Cortes para que los decretos fueran tenidos y obedecidos como leyes. En este sentido el modelo sería más parecido al anglosajón de bill of indemnity ${ }^{5}$, institución conocida en España como muestran los debates parlamentarios (Diario de Sesiones de las Cortes Constituyentes, $\mathrm{n} .^{\circ} 96,10$-junio-1869).

De esta manera, aunque los principios y propósitos de la Revolución de 1868 contrasten a primera vista con un desbordante recurso al decreto como instrumento dispositivo ante la emergencia, del mencionado deslinde teórico de los campos propios de Parlamento y Gobierno surge la necesidad de "sanar" los que hoy llamariamos decretos-leyes, añadiendo a estas disposiciones que estarían ya dotadas de la legitimidad de la Revolución de septiembre, el sello de legalidad que les faltaba. Así, en el artículo único del proyecto de ley del Gobierno remitido a las Cortes se decía:

"Todos los decretos que el Gobierno provisional dictó y publicó desde su instalación hasta la de las Cortes Constituyentes como Poder Legislativo en el ejercicio de la soberanía de que estaba inves-

4 Hauriou, M., Précis de Droit Administratif et Droit Public Général, Paris, 1903 , págs. 30 y ss.

5 Sobre los precedentes del modelo de convalidación parlamentaria de los decretos-leyes nos remitimos a nuestro estudio "La convalidación parlamentaria del decreto-ley en Españan, Revista de las Cortes Generales, n. ${ }^{\circ} 44,1998$, págs. 11 y ss. 
tido por la revolución de septiembre, se tendrán y obedecerán como leyes mientras las Cortes no decreten su reforma o derogación».

Este proyecto de ley de conversión de decretos es una buena muestra de los principios que inspiraban la revolución, y en particular del dogma demoliberal de la ley como expresión de la voluntad general, que sólo puede ser producto de la institución parlamentaria. Por eso, esta primera intervención de las Cortes para dar a los decretos del Gobierno fuerza de ley, nos parece un testimonio extraordinario de los nuevos aires de aquella Revolución liberal de 1868.

\section{LA REVOLUCIÓN DE 1868 Y EL GOBIERNO POR DECRETO}

El 29 de septiembre de 1868 se abría por última vez la Gaceta de Madrid con el que era habitual parte oficial: «S.M. la Reina Nuestra Señora (Q.D.G.) y su Augusta Real familia continúan sin novedad en su importante salud".

La septembrina llega así a la Gaceta de Madrid el 30 de septiembre, con la sustitución del escudo de la Casa de Borbón por una figura de mujer, más evocativa de la República que de cualquier otra forma de Gobierno. Dejando a un lado los símbolos, en lo que aquí nos importa, esta publicación oficial se convertirá en testigo inmediato de los vaivenes en el poder que marcan el Sexenio Revolucionario.

Desde septiembre de 1868 a febrero del año siguiente, el poder es ejercido de manera extraordinaria por el Gobierno Provisional presidido por el General Serrano, duque de la Torre. Por eso, hasta la instalación de las Cortes Constituyentes en enero de 1869, la producción de disposiciones responde al modelo típico de las etapas de crisis o emergencia constitucional, en las que el desorden es la regla general y el establecimiento de todo tipo de disposiciones con independencia de la naturaleza y la eficacia se hace por decreto. El Gobierno Provisional ejerce el poder soberano como depositario de la soberania y del espíritu de la Revolución. Asi lo reclama para si en un Manifiesto publicado el 26 de octubre en la Gaceta de Madrid, por el que asume plenos poderes para poner fin al caos generado por la intervención de las Juntas Revolucionarias, $y$, al final, anuncia que en su día dará cuenta a las Cortes Constituyentes ${ }^{6}$.

6 Gaceta de Madrid, 26 de octubre de 1868. 
A partir de ese momento, el decreto se convierte en instrumento dispositivo hegemónico bajo la que es su configuración típica de las épocas de crisis, revolución o cesura histórica: instrumento dispositivo de quien detenta el poder soberano para resolver de manera firme ante la emergencia?.

Tras la revolución de septiembre 1868 serán más de cien los decretos emitidos por el Gobierno Provisional por los que se adoptarán medidas de muy diversa índole y eficacia: de organización, de derechos y libertades, legislativas, o, en fin, administrativas. Destacamos los siguientes: Decreto por el que el Gobierno Provisional asume el poder supremo (Gaceta de Madrid, 5-X-1868); D. de disolución de la Compañía de Jesús (Gaceta de Madrid, 13-X-1868); D. por el que se declara la libertad de emitir libremente pensamientos (Gaceta de Madrid, 24-X-1868); D. por el que se deroga la Ley de instrucción primaria y se proclama la libertad de primera enseñanza (Gaceta de Madrid, 15-X-1868); D. por el que se adopta un nuevo sistema monetario, se ordena la reacuñación de moneda y se establece la peseta como unidad monetaria (Gaceta de Madrid, 19-X-1868); D. por el que se pone en vigor la Ley Municipal (Gaceta de Madrid, 22-X-1868); D. por el que se restablece la vigencia de la Ley de 30 de enero de 1856 sobre el Convenio de Vergara (Gaceta de Madrid, 13-X-1868); D. sancionando el libre derecho de asociación (Gaceta de Madrid, 21-X-1868);

7 En otro trabajo nos hemos ocupado de todos estos aspectos en torno a la institución del decreto, en general y en España. Baste aquí con recordar que, precisamente el origen de la palabra misma remite a la idea de decisión de voluntad especialmente enérgica que resuelve ante una disyuntiva o crisis. La voz «decreto" deriva del verbo latino decerno, -ere, -crevi, -cretum, con el que se designaba la acción de resolver o dirimir un conflicto de intereses, y singularizaba el acto de voluntad dictado para zanjar una cuestión controvertida. Si en sus primeras aplicaciones la voz "decreto" se empleó en Roma para un tipo peculiar de decisiones adoptadas por los magistrados cum iurisdictione, más tarde se reservó también para las sentencias irrevocables del Emperador. Así a la nota de resolver ante la disyuntiva se unió la de máxima autoridad. Con el tiempo la expresión "decreto» se generalizó con el significado de decisión firme de quien detenta la máxima autoridad en la crisis. Son abundantes las manifestaciones históricas del decreto bajo esa configuración del instrumento dispositivo del soberano en la crisis. Recuérdese cómo las Cortes de Cádiz, cuyo espíritu asoma también en esta Revolución de 1868 , recurrieron a esta figura para exteriorizar sus principales acuerdos. Estas seguian a su vez el ejemplo de la Asamblea Nacional Francesa que por decreto, entre otras cosas, habría aprobado la Declaración de Derechos del Hombre y del Ciudadano (Decreto de 26 de agosto de 1789) o el de la Convención de 21 de septiembre de 1792 que abolió la Monarquía y proclamó la República. Sobre todo esto véase nuestro trabajo El gobierno por decreto, Pamplona, 1997, págs. 21 y ss. 
o, finalmente, la disposición que aparece en la Gaceta como Ley electoral o decreto sobre el ejercicio del sufragio universal (Gaceta de Madrid, 9-XI-1868).

Durante estos meses de Gobierno Provisional la exteriorización de las disposiciones en la publicación oficial reviste, como decimos, la forma de decreto. Se prescinde de la expresión "real», indicativa de la procedencia regia, que se retomará con la llegada al trono de Amadeo de Saboya, sin que de ello pueda concluirse una participación del Rey en la facultad de decretación. El escaso peso efectivo del monarca en el laberinto del poder haría que la expedición de los reales decretos tuviera más de formularia que otra cosa.

Otro elemento a destacar es que aparecen como decreto no sólo las decisiones del Gobierno Provisional o del Presidente del mismo, sino también las firmadas individualmente por los Ministros: "En uso de las facultades que me corresponden como miembro del Poder Ejecutivo y Ministro ... vengo en decretar lo siguiente...". En este sentido, téngase en cuenta que en el sistema previo a la Revolución, a los ministros no se les reconocía todavía facultad decisoria propia en el ámbito de su departamento, y que la exteriorización de las disposiciones ministeriales observaba la forma de Real Orden, que indicaba que el ministro se limitaba a transmitir con carácter general o a las autoridades subordinadas una decisión "de orden del Rey" ${ }^{8}$. Por eso, aunque no deja de ser extraña esta formulación de las decisiones ministeriales, hay que tener en cuenta que el precedente inmediato no es válido como modelo de referencia. Ante este vacío, el recurso al decreto como cauce de exteriorización de todo tipo de decisiones, incluso con independencia de los sujetos, de alguna manera, vendría a mostrar la identificación de la institución con las notas de autoridad en la crisis y resolución firme e inmediata.

También durante la I República, proclamada el 11 de febrero de 1873, tras la renuncia de Amadeo de Saboya, se recurrió al gobierno por decreto. La inestabilidad social y política, las guerras en curso y el acuerdo del Poder Ejecutivo de la República (Decreto de 24 de abril de 1873) disolviendo la Comisión Permanente de al Asamblea hicieron que otra vez el decreto se convirtiera en instrumento dispositivo hegemónico.

8 Sobre los origenes de la figura de la Orden Ministerial y su evolución desde la Real Orden nos remitimos al trabajo de GaRcla CuAdrado, A. M., El gobierno por orden ministerial, Eunsa, Pamplona, 1986. 
Tanto el Gobierno Provisional nacido en septiembre de 1868 como el que asumiera plenos poderes en la I República advirtieron lo extraordinario del momento y la voluntad de someter lo decidido por decreto a las Cortes Constituyentes (Gaceta de Madrid, 26 de octubre de 1868 - Manifiesto del Gobierno provisional-, y Gaceta de Madrid, 9 de enero de 1874 - Manifiesto del Nuevo gobierno a la Nación-).

\section{EL PROYECTO DE LEY DE CONVERSIÓN DE LOS DECRETOS DEL GOBIERNO PROVISIONAL}

Tras la reunión de las Cortes Constituyentes en febrero de 1869 se va a restablecer, aunque con cierta precariedad, el modelo tradicional de reparto de funciones entre Parlamento y Gobierno y, en consecuencia el dominio de la ley y el propio del decreto. Recuérdese que en España el modelo tradicional de reparto es el que ya se afirmara en el sistema de la Constitución gaditana de 1812, donde la reserva de la ley era total y sin distinción de materias, quedando al Gobierno en lo normativo una función reglamentaria de desarrollo. Por tanto, el decreto como instrumento dispositivo propio del gobierno quedaba plegado a la de normación secundaria y subordinada ${ }^{9}$.

De esta forma, las Cortes, al tiempo que elaboran la Constitución de 1869 , desempeñan también una importante función legislativa ${ }^{10} y$, en lo normativo, el Gobierno se limita a la función reglamentaria de desarrollo de la ley. Vuelve así el decreto a su función de instrumento dispositivo del Gobierno de rango subordinado a la ley en el establecimiento de disposiciones generales.

Pues bien, superada la fase de concentración de poderes, el Gobierno Provisional presentó en las Cortes un proyecto de ley de conversión de los decretos dictados desde septiembre de 1868. Dicho pro-

9 Así será el modelo tradicional español, con las excepciones de 1852 y 1929. Sobre el tema nos remitimos a la obra de GALlego ANABITARTE, A., Ley y reglamento en el Derecho Público occidental, IEA, Madrid, 1971, págs. 30 y ss.

10 Durante este período se aprobaron importantísimas leyes, entre otras las siguientes: Ley provisional del matrimonio civil (Gaceta de Madrid, 21-V-1870), Ley provisional del Registro civil (Gaceta de Madrid, 20-VI-1870), Ley provisional sobre la reforma de la casación civil (Gaceta de Madrid, 22-VII-1870); Ley del procedimiento penal (Gaceta de Madrid, 18-VI-1870); Ley de extranjería (Gaceta de Madrid, 6-VII-1870), Ley de abolición de la esclavitud (Gaceta de Madrid, 6-VII-1870); o, en fin, la Ley electoral (Gaceta de Madrid, 21-VIII-1870). 
yecto de ley de conversión, además de novedoso, nos parece un buen ejemplo del espíritu que impregna la revolución misma. En modo alguno estaba obligado el Gobierno a llevar a las Cortes las medidas adoptadas por decreto, $y$ sin embargo lo hace para udar a las medidas legislativas dictadas por el Gobierno provisional en el uso de la soberanía de que le invistió la revolución de septiembre, el voto y la sanción de las Cortes Constituyentes para que decretos de tan grave trascendencia tengan la autoridad que hoy les falta, imprimiendo en ellos un sello de legalidad que sea indiscutible en todo tiempo ${ }^{11}$. Téngase en cuenta que en la España de aquella época, lo que llamamos hoy «decretoley" no estaba contemplado, y la expresión misma, aunque como hemos dicho antes, ya circulaba en Europa desde principios del siglo $X I X$, era desconocida en la práctica española12. Sin embargo; los perfiles de los decretos así dictados, con independencia del nombre, nos permiten reconocer en ellos un precedente de la institución que hoy se recoge en el art. 86 de nuestra Constitución.

El procedimiento parlamentario para la tramitación de este peculiar proyecto de ley tuvo que improvisarse, y dio lugar a un interesante debate acerca del sentido de esta intervención a posteriori de las Cortes sobre unas medidas legislativas puestas ya en vigor.

Una Comisión formada por siete diputados estudió el proyecto de ley remitido por el Gobierno Provisional. En dicho Dictamen la Comisión, aparte de señalar la ausencia de precedentes en España, entiende que el proyecto de ley es ante todo un homenaje de respeto a las Cortes Constituyentes. Pero además, responde a la conveniencia de que «ante las eventualidades futuras, las medidas legislativas adoptadas en su día por el Gobierno en uso de la soberanía de que le invistió la Revolución, reciban el voto y la sanción de las Cortes para que tengan la autoridad que hoy les falta, imprimiendo en ellas un sello de legalidad indiscutible en todo tiempon.

11 Diario de Sesiones de las Cortes Constituyentes, n. ${ }^{\circ} 41$, apéndice $4 .^{\circ}, 3$ abril 1869.

12 Con probabilidad, la primera previsión de la figura del decreto-ley en España es la que se hace en el decreto de 15 de septiembre de 1923 por la que se autoriza a Primo de Rivera, como Presidente del Directorio Militar «a proponer al monarca, cuantos decretos convengan a la salud pública, los que tendrán fuerza de ley interin en su dia no sean modificados por leyes aprobadas por las Cortes del Reino". En virtud de esta autorización se dictaron numerosos decretos-leyes. Sin embargo, habrá que esperar a la Constitución de 1931 (art. $80 \mathrm{CE}$ ) para encontrar recogida la institución del decreto-ley con un perfil más parecido al que tiene en nuestros dias. 
En cuanto al objeto, para la Comisión se trataba de ratificar exclusivamente aquellas medidas que, aprobadas en su día por decreto, eran medidas de carácter legislativo, y no aquellas cuya naturaleza era administrativa y por tanto caían dentro de la competencia del Ejecutivo.

Pues bien, precisamente la finalidad de la intervención parlamentaria - dar el sello de legalidad a aquello que se habia con la legitimidad de la emergencia de la revolución ante eventualidades futuras - y el objeto - exclusivamente aquellos decretos aprobatorios de medidas legislativas - nos permiten apreciar en este episodio de la vida parlamentaria española el primer precedente de la institución que hoy llamamos la convalidación parlamentaria de los decretos-leyes.

Con importantes diferencias, también en la actualidad esta intervención prevista en el artículo 86.2 CE y regulada en el artículo 151 del Reglamento del Congreso, además de ser un instrumento de control parlamentario sobre la acción del Gobierno, tiene una vertiente legislativa, pues afecta a la eficacia de las disposiciones legislativas aprobadas por el Gobierno, que una vez ratificadas por el Congreso pierden la provisionalidad ${ }^{13}$. En aquella intervención de las Cortes de 1869 se buscaba que los decretos adquirieran una fuerza legislativa indiscutible «ante las eventualidades futuras».

En cuanto a la concreta tramitación parlamentaria de aquel proyecto de ley, el principal problema que se planteó fue el de si la conversión de decretos había de ser en bloque o, si por el contrario, era posible presentar enmiendas o distinguir entre los numerosísimos decretos de eficacia legislativa aprobados en la Revolución. Mientras el Gobierno, bien defendido en sus intereses por la Comisión parlamentaria, entendía que la sanción de las Cortes había de darse o negarse a la totalidad de los decretos "legislativos", algunos diputados presentaron enmiendas por las que expresamente se excluían determinados decretos. Finalmente, las enmiendas no fueron admitidas a trámite, aunque su presentación sirvió de acicate para una interesante discusión acerca del sentido del proyecto de ley de conversión remitido por el Gobierno.

El parecer del Gobierno era defendido por la Comisión que entendía su tarea limitada a proponer a las Cortes «la sanción de las

13 De la Iglesia Chamarro, M. A., La convalidación parlamentaria..., págs. 45 y ss. 
medidas legislativas de aquel Gobierno, mientras la Asamblea en el ejercicio de sus altas prerrogativas, no las deroga total o parcialmente, introduciendo en ellas alteraciones que estime como buenas en su elevado criterio." Y sigue más adelante "firme la Comisión en esta idea ni siquiera se ha ocupado de examinar y discutir la bondad de esas medidas en su conjunto ni en sus antecedentes. Propone a las Cortes su aprobación con un carácter interino y provisional, pero sin que esta aprobación comprometa la iniciativa del Diputado y del Poder ejecutivo." (Dictamen de la Comisión, Diario de Sesiones de las Cortes Constituyentes, $\left.\mathrm{n} .^{\circ} 96,10-\mathrm{VI}-1869\right)$.

El Gobierno, a través de la Comisión parlamentaria, sostuvo la legitimidad revolucionaria de los decretos dictados, así como la teoría de rendir un tributo a las Cortes con la presentación del proyecto de ley de conversión ${ }^{14}$. Para el Ejecutivo, con el proyecto de ley no se buscaba sanar unos actos viciados en origen, sino dar la estabilidad de la ley a las medidas adoptadas por decreto, que una vez convertidas en ley, podían ser derogadas o modificadas a iniciativa de las Cortes o del Ejecutivo.

La oposición, por su parte, presentó siete enmiendas solicitando la no ratificación parlamentaria de determinados decretos. A su juicio, el proyecto de ley no podía ser entendido sino como un bill de indemnidad, cuyo objeto era sanar los decretos dictados por el Gobierno provisional, y dicha sanación sólo podía darse distinguiendo entre las distintas medidas legislativas aprobadas en su día por el Gobierno de septiembre (Diario de Sesiones de las Cortes Constituyentes, n. ${ }^{\circ}$ 96, 10-junio-1869).

Más allá de la discusión generada por el proyecto de ley de conversión de los decretos en leyes, nos parece interesante el hecho en sí de su presentación, así como la delimitación del objeto a las medidas legislativas. El proyecto de ley, entendemos, refleja esa delimitación de los campos propios de la ley y el decreto o, dicho de otro modo, de Parlamento y Gobierno. Otra cosa es que los intereses políticos del momento desdibujaran el sentido de la votación al limitar el alcance del voto de las Cortes y tener que justificar la aprobación en bloque de todos los decretos.

A pesar de la distancia y lo distinto de los planteamientos de entonces y los de nuestros días, la ratificación parlamentaria tiene, en

14 Esta parte de los debates puede seguirse en el Diario de.Sesiones de las Cortes Constituyentes, n. ${ }^{\circ} 96,10-\mathrm{VI}-1869$. 
parte, un sentido parecido a la que en aquel momento quiso darle el Gobierno. En la actualidad no se trata de "sanar" el decreto ley como un acto que adolece de un vicio en origen, sino de dar estabilidad y fijeza a unas medidas legislativas adoptadas por decreto. Además, aunque entonces el tema se planteó en bloque sobre los decretos del Gobierno provisional, también hoy la votación lo es de totalidad, y cualquier reforma sobre el texto ha de llevarse a cabo en la tramitación como proyecto de ley del decreto-ley convalidado.

En cualquier caso, esta intervención parlamentaria a instancia del Gobierno para que se tuvieran y obedecieran como leyes los decretos de contenido legislativo es, como decíamos más arriba, reflejo en parte de la intención que impulsó la Revolución liberal de 1868, proyectada en concreto sobre el concepto mismo de ley, el papel de las Cortes y la distribución de las facultades normativas entre los órganos políticos principales.

Hasta aquí estas notas sobre un episodio de la vida política y parlamentaria española que, como en tantas otras cuestiones, muestra la riqueza de nuestra historia en general, y parlamentaria en particular, como fuente para conocer las raíces propias de las actuales instituciones y, en el caso concreto, de la convalidación parlamentaria de los decretos-leyes. 